\title{
Rising toll from AIDS in Japan prompts big jump in spending
}

Tokyo. Japan is at last waking up to the dangers of AIDS. The Ministry of Health and Welfare last week responded to a sharp rise this year in the number of reported cases of infection by human immunodeficiency virus (HIV) by requesting a fivefold increase in fiscal year 1993, starting on 1 April, for its tiny budget to fight AIDS. Nearly half of the proposed budget would go to research, with the rest invested in public education, screening, treatment and counselling.

But critics say that even a fivefold increase falls far short of what is required. This year, the government will spend only a little more than $¥ 2$ billion (US\$16 million) to combat AIDS.

Japan has few AIDS patients compared with the United States, Europe and some South-East Asian nations. The official total, including those who have died, stands at just under 500 , but many cases are said to go unreported because of fear of discrimination. However, in the first six months of this year, 226 new cases of HIV infection were reported, almost the same number as in the whole of last year.

A change in the affected population is also driving the increased support. Many of those newly infected are believed to have contracted the virus through heterosexual sex, whereas in the past the majority of reported cases were among haemophiliacs and homosexuals. This development has heightened public concern and awareness of AIDS.

The government made its first major investment in fiscal year 1988 after the first Japanese woman died of AIDS. But public concern subsided rapidly and the annual budget has remained frozen at $¥ 2$ billion without even increases to cover inflation.

Next year, however, the ministry would like $¥ 10.3$ billion. The request has to be screened by the Ministry of Finance and approved by the Diet, but such requests seldom undergo significant change.

Nearly half of the budget, $¥ 4.8$ billion, would go to research and the development of drugs and vaccines; this figures includes $¥ 576$ million for the World Health Organisation. One of the nation's major centres for AIDS research is at the National Institute of Health, whose researchers are moving into a controversial new building (see page 703). Shudo Yamazaki, director of the centre, says that his institute asked for a tenfold increase but expects to receive less than half that amount.

A significant portion of the increased budget will be used for public education. Ignorance and prejudice about AIDS are widespread: many hospitals refuse to treat those with AIDS for fear of frightening away other patients, while others refuse to acknowledge that they care for patients with HIV.

Only two hospitals, both in Tokyo, spe-
The health ministry provides the lion's share of government funding for AIDS research, although the Ministry of Education, Science and Culture (MESC) and the Sci-

\section{Japan carves up a bigger AIDS pie}

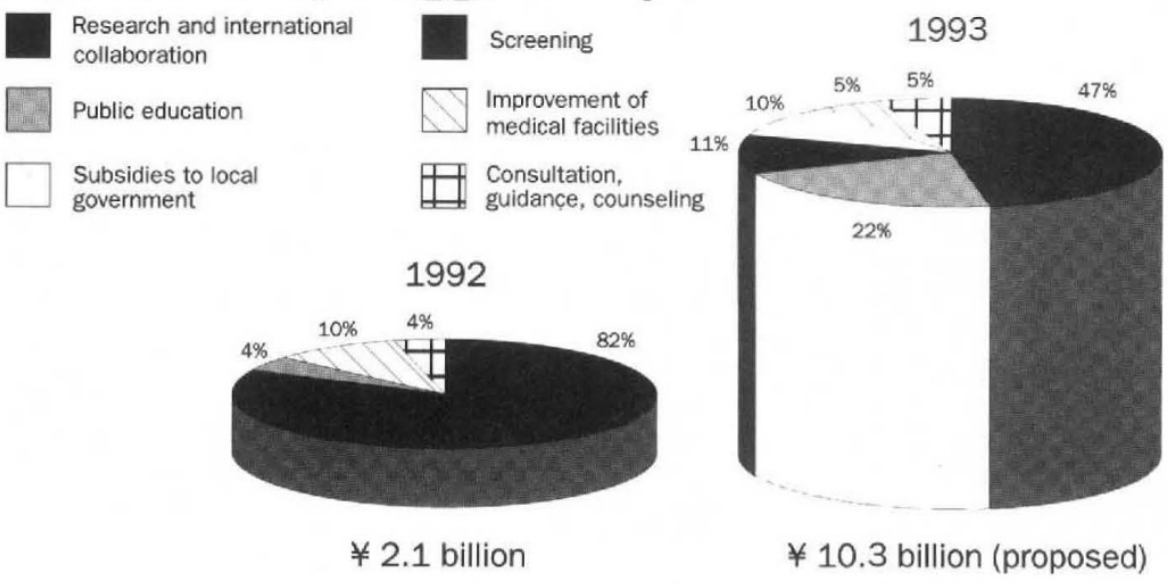

cialize in the treatment of AIDS patients the Institute of Medical Science of Tokyo University and Tokyo Komagome Hospital. The ministry would like to establish similar centres in other parts of the country. Officials also plan to establish Japan's first hospice for the treatment of terminally ill AIDS patients, although critics say that the 20-bed facility falls woefully short of what is needed.

ence and Technology Agency (STA) also provide some support. Although these two agencies are said to be considering ways to increase their support, any increases are likely to come at the expense of other programmes, such as the human genome project. Their intentions will be spelled out in 1993 budget requests due in the next few weeks.

David Swinbanks

\section{Ways to keep Mars 'clean'}

A report from the US National Research Council has allayed fears that a proposed European mission to Mars might be jeopardized by demands for stringent standards of planetary protection (see Nature 358, 443; 1992). The report*, commissioned by the US National Aeronautics and Space Administration (NASA) in advance of next week's World Space Congress in Washington, says that probes landing on Mars need not be sterilized as long as they are not conducting exobiological experiments.

Researchers at the European Space Agency (ESA) feared that such a requirement would break the budget for its proposed Marsnet project, which is intended to study the planet's meteorology and seismic activity. Because its mission is non-biological, however, the project would require only a thorough cleaning during assembly.

Ken Nealson of the University of Wisconsin-Milwaukee, chair of the committee that produced the report, says that the committee feels that any contamination from a non-exobiological probe such as Marsnet is unlikely to spread beyond the landing site. If such a probe discovered an environment favourable to life, a subsequent probe could examine that possibility by landing beyond the possible sphere of contamination.

However, the planetary protection standards are likely to get tougher for probes whose main purpose is exobiological. The report says that the increased sensitivity of methods to detect biological material developed since the Viking missions of the 1970s demand equally stringent sterilization procedures.

The report also emphasizes the importance of gathering data from a range of martian sites. "Until such data are available", it says, "it will be impossible to make informed decisions concerning landings for in-depth biological study." lan Mundell

* Biological Contamination of Mars - Issues and Recommendations (Space Studies Board, National Research Council, 2101 Constitution Avenue NW, Washington, DC 20418). 